\title{
SÍNDROME DE STEVENS-JOHNSON ASSOCIADA A FENITOÍNA EM PÓS-OPERATÓRIO DE HEMORRAGIA INTRAPARENQUIMATOSA CEREBRAL: RELATO DE CASO
}

\section{STEVENS-JOHNSON SYNDROME ASSOCIATED WITH PHENYTOIN IN BRAIN INTRAPARENCHYMAL HEMORRHAGE POSTOPERATIVE: CASE REPORT}

\begin{abstract}
Humberto Codagnoni Neto ${ }^{1 *}$, Bruno Frison Chagas ${ }^{1}$, Mauricio Zandoná Soares ${ }^{1}$, Renato Endler Lachinski $^{2}$, Vagner Fagnani Linartevichi ${ }^{3}$
\end{abstract}

${ }^{1}$ Acadêmico de Medicina do Centro Universitário Assis Gurgacz, ${ }^{2}$ Médico, docente do Centro Universitário Assis Gurgacz, ${ }^{3}$ Farmacêutico, docente do Centro Universitário Assis Gurgacz

*Autor correspondente: humberto cn@hotmail.com, https://orcid.org/0000-0003-0782-0223

\section{RESUMO}

A Síndrome de Stevens-Johnson é uma reação idiossincrática grave e rara que atinge em torno de 1,2 a 6 pessoas por milhão de pessoas por ano. É causada na maioria das vezes, $50 \%$ a $80 \%$, por uma reação de hiperssensibilidade tardia à fármacos, porém, outras etiologias, como infecções bacterianas e virais também podem desencadear a síndrome. É caracterizada por lesões mucocutâneas com padrão eritematoso ou purpúrico, que confluem em tronco e face que aparecem após 4 a 28 dias do início do uso da medicação. A maior complicação da Síndrome de Stevens-Johnson é a sepse, e a mortalidade geralmente não ultrapassa $5 \%$. O tratamento inicial é feito com a retirada das medicações, que possivelmente estão causando a síndrome, e por medidas de suporte. Neste trabalho foi relatado o caso de uma paciente do sexo feminino de 56 que apresentou lesões de pele, compatíveis com a Síndrome de Stevens-Johnson, após fazer o uso de fenitoína concomitante com sulfametoxazol-trimetroprima, para profilaxia de crises convulsivas após realização de neurocirurgia para drenagem de hematoma intraparenquimatoso por complicação de ressecção de tumor cerebral e para tratamento de infecção do trato urinário, respectivamente. A paciente teve boa evolução clínica das lesões após a retirada da medicação.

Palavras-chave: Síndrome de Stevens-Johnson. Reação adversa a medicamento. Fenitoína.

\begin{abstract}
The Stevens-Johnson sindrom is a rare and serious idiossincratic reaction which reaches around 1.2 to 6 people per million people per year. It is coused in the most of times, 50\% to $80 \%$, due to a late hypersensitivity reaction to drugs, however, other etiologies such as bacterial and viral infections can also trigger the syndrome. It is characterized by mucocutaneous lesions with erythematous or purpuric pattern, that converge in to the trunk and face and appear 4 to 28 days after the beginning of the medication use. The main complication of Stevens-Johnson sindrom is sepsis, and mortality generally does
\end{abstract}




\section{FAG JOURNAL OF HEALTH}

not exceed 5\%. The initial treatment is made with the withdrawal of medications, that are possibly causing the syndrome, and by supportive measures. This article reports the case of a 56-year-old female patient who presented skin lesions that are compatible with Stevens-Johnson sindrom after concomitant use of phenytoin with trimethoprim sulfamethoxazole for seizure prophylaxis after neurosurgery for intraparenchymal hematoma drainage due to the complication of brain tumor resection and for treatment of urinary tract infection, respectively. The patient had a good clinical evolution of the lesions after medication withdrawal.

Key-words: Stevens-Johnson Syndrome. Adverse drug reaction. Phenytoin.

\section{INTRODUÇÃO}

A Síndrome de Stevens-Johnson (SSJ) foi descrita pela primeira vez em 1922, como uma síndrome mucocutânea aguda em dois garotos. A condição foi caracterizada como uma conjuntivite purulenta severa e estomatite severa com necrose de mucosa extensa e com máculas purpúricas (HARR e FRENCH, 2010). Em 1956 foi descrito, por Allan Lyell, uma erupção de pele que parecia com queimaduras, que foi chamada de Necrólise Epidérmica Tóxica (NET). Com o passar do tempo a SSJ e a NET foram consideradas dois finais de um espectro de severas reações medicamentosas que somente são diferenciadas pela extensão das lesões de pele (HARR e FRENCH, 2010). A diferenciação das duas patologias se dá pela classificação de Bastuji-Garin, sendo que a SSJ é quando o desprendimento da epiderme não ultrapassa $10 \%$ da superfície corporal e a NET é quando o desprendimento da epiderme chega a mais de $30 \%$ da superfície corporal. Quando o desprendimento da epiderme fica entre 10\% e 30\% da superfície corporal trata-se uma superposição das duas condições (ARRUDA e SAMPAIO, 2014) (BASTUJI-GARIN, RZANY, et al., 1993).

No Brasil as estatísticas quanto a incidência e prevalência da SSJ e NET são escassas, na Europa e Estados Unidos a literatura traz que a prevalência de SSJ e NET é de aproximadamente de 2 a 3 pessoas por milhão por ano (WONG, MALVESTITI e HAFNER, 2016).

A incidência da SSJ é em torno de 1,2 a 6 pessoas por milhão de pessoas por ano, já a NET se estima de 0,4 a 1,2 casos por milhão de pessoas por ano. Podem acontecer em qualquer idade, porém são mais frequentes em maiores de 40 anos (WOLFF, JOHNSON e SAAVEDRA, 2015). Em relação ao gênero, a NET é mais comum em 


\section{FAG JOURNAL OF HEALTH}

mulheres e a SSJ ocorre mais na população masculina (WONG, MALVESTITI e HAFNER, 2016).

As diferenças de prescrição de medicamentos em diversos locais, o perfil genético dos pacientes, a presença de câncer ou exposição a radioterapia podem ter um impacto na variação da incidência de SSJ em diversas regiões (HARR e FRENCH, 2010).

Alguns fatores de risco também são correlacionados ao aparecimento da síndrome, como por exemplo múltiplas comorbidades, pacientes polimedicados, fatores genéticos, imunossupressão e uso concomitantes de anticonvulsivantes e radioterapia (WONG, MALVESTITI e HAFNER, 2016). Alguns fatores genéticos que predispões a SSJ já são descritos, como por exemplo a identificação do alelo HLA-B*1502, que é um fator predisponente para desenvolvimento de SSJ com uso de carbamazepina, o HLA-B* associado a lamotrigina, HLA-B ${ }^{\star} 5901$ associado a metazolamida, HLA-B ${ }^{\star} 7301$ associado aos anti-inflamatórios não esteroides (AINEs) da categoria dos oxicans e o HLA-B*3802 relacionado ao sulfametoxazol (AZULAY, 2013). Estes alelos são responsáveis por enzimas que estão envolvidas na destruição de metabólitos de drogas tóxicas, e esses indivíduos que têm essa deficiência são chamados de acetiladores lentos (WONG, MALVESTITI e HAFNER, 2016).

A SSJ é caracterizada por uma reação idiossincrática grave, mais comumente desencadeada após 4 a 28 dias de uso de medicações, em $30 \%-50 \%$ dos casos (D'AVILA, FIGUEIREDO e TEIXEIRA, 2012), e tem duração média de 4 semanas (AZULAY, 2013). A SSJ e a NET têm um perfil reativo polietiológico, porém os fármacos são sem dúvidas o principal fator causal. Também substâncias químicas, pneumonia por Mycoplasma, infecções virais, sendo o herpes simples vírus o maior causador com 19,7\% dos casos, e vacinações podem desencadear quadros de SSJ e NET (WOLFF, JOHNSON e SAAVEDRA, 2015) (WONG, MALVESTITI e HAFNER, 2016).

Acredita-se que as drogas são as maiores causadoras da SSJ, em torno de 50 a $80 \%$ dos casos e na NET em torno de $80 \%$. As drogas mais comuns são as sulfonamidas e penicilinas, totalizando $26 \%$ dos casos. Porém, existem mais de 100 medicações, de várias classes, capazes de causar SSJ ou NET. Algumas delas estão classificadas em relação ao risco causador. As de alto risco são o alopurinol, carbamazepina, sulfassalazina, lamotrigina, nevirapine, AINEs derivados dos oxicans, fenobarbital e 


\section{FAG JOURNAL OF HEALTH}

fenitoína. As classificadas como risco moderado são as cefalosporinas, macrolídeos, quinolonas, tetraciclinas e AINEs derivados do ácido acético. Já as de baixo risco são os betabloqueadores, inibidores da enzima conversora de angiotensina, inibidores do canal de cálcio, diuréticos tiazídicos, insulina, AINEs derivados do ácido propiônico (WONG, MALVESTITI e HAFNER, 2016).

O risco de usuários novos para cada 10.000 pessoas de desenvolver SSJ/NET é de aproximadamente 8,3 para a fenitoína, 1,4 para carbamazepina, 2,5 para lamotrigina, 8,1 para fenobarbital e 0,4 para ácido valpróico. O risco relativo para desenvolver a SSJ/NET com fenitoína é de 9,6 (IC 95\%, 2,0-46,6). Sendo que o risco para desenvolver SSJ com a administração simples de fenitoína é mais comum no início do tratamento (D'AVILA, FIGUEIREDO e TEIXEIRA, 2012).

A patogênese básica é de uma reação de hipersensibilidade tardia ao fármaco, que se dá pela deposição dos componentes do complemento e imunoglobulina (lgG) nas junções dermo-epidérmicas e ao redor de pequenos vasos da derme, ocorre então a expressão, pelos queratinócitos, do antígeno leucocitário humano (HLA-DR), que é similar a outras desordens inflamatórias da pele. As células T CD8+ reconhecem o complexo maior de histocompatibilidade I (MHC-I) e desencadeiam as lesões de pele da SSJ (BULISANI, SANCHES, et al., 2006).

Em casos de lesões que mimetizem o eritema polimorfo, a possibilidade de etiologia infecciosa deve ser considerada. O mecanismo que desencadeia as lesões por etiologia infecciosa parece ser por linfócitos citotóxicos, que induzem a apoptose maciça pela ativação dos receptores Fas, por meio de linfocinas IL-6, IL-10 e do fator de necrose tumoral-alfa (TNF-a) (AZULAY, 2013).

Alguns sinais prodrômicos podem ocorrer aproximadamente uma semana antes do surgimento das lesões, como por exemplo febre, mal-estar, cefaleia, tosse e dor de garganta (ARRUDA e SAMPAIO, 2014).

A manifestação típica são lesões mucocutâneas com padrão eritematoso ou purpúrico, geralmente formando placas ou máculas em formato de alvo que confluem em tronco e face. Atingem seu pico máximo em 4 dias e são precedidas por mal-estar e febre normalmente. (D'AVILA, FIGUEIREDO e TEIXEIRA, 2012). As complicações e sequelas mais frequentes da SSJ e da NET são sepse, que pode ser fatal se não reconhecida e 


\section{FAG JOURNAL OF HEALTH}

tratada, ceratoconjuntivite, Hiper ou hipopigmentação da pele, distrofias das unhas, olho seco, e outras complicações oculares (EMERICK, RODRIGUES, et al., 2014).

O acometimento de mucosas pode preceder ou ocorrer depois das lesões de pele. Geralmente se inicia com um exantema e edema que causa erosões e formação de pseudomembrana nas mucosas. As mais acometidas são os olhos, boca, genitais, laringe e vias aéreas superiores (WONG, MALVESTITI e HAFNER, 2016). Em torno de 10 a 30\% dos casos tem o aparecimento de febre e de lesões no trato gastrointestinal e respiratório (WONG, MALVESTITI e HAFNER, 2016).

A mortalidade na SSJ geralmente não ultrapassa $5 \%$, sendo a sepse a causa mais importante de morte. O prognóstico não está relacionado com o tipo ou a dose da droga causadora ou se o paciente tem HIV, mas sim com a suspensão da droga causadora (BASTUJI-GARIN, RZANY, et al., 1993) (ENSINA, FERNANDES, et al., 2009).

O escore de gravidade de SCORTEN faz uso de alguns parâmetros para avaliar o prognóstico do paciente e facilitar a adoção de medidas necessárias, os parâmetros são: descolamento da epiderme maior do que $10 \%$, idade maior que 40 anos, neoplasias, frequência cardíaca acima de $120 \mathrm{bpm}$, dosagem de ureia maior do que $28 \mathrm{mg} / \mathrm{dL}$, glicemia maior do que $252 \mathrm{mg} / \mathrm{dL}$ e bicarbonato sérico maior do que $20 \mathrm{mg} / \mathrm{dL}$ (AZULAY, 2013).

A taxa de mortalidade que se dá pelo score de SCORTEN é a seguinte: nenhum ou apenas um dos parâmetros presentes: a taxa de mortalidade é de 3,2\%; 2 parâmetros presentes: mortalidade de 12,1\%;3 parâmetros presentes: mortalidade de 35,3\%; 4 parâmetros presentes: mortalidade de $58,3 \%$; 5 ou mais parâmetros: mortalidade de $90 \%$ (BASTUJI-GARIN, RZANY, et al., 1993) (WONG, MALVESTITI e HAFNER, 2016) (EMERICK, RODRIGUES, et al., 2014).

Cicatrizes de pele geralmente não são deixadas pelas lesões, porém nas lesões de mucosas podem ocorrer estreitamentos e sangramentos e estão presentes em 73,0\% dos casos, sendo a mucosa oral e esofagiana as principais (BULISANI, SANCHES, et al., 2006) (EMERICK, RODRIGUES, et al., 2014). Pode ocorrer, em 62,5 dos casos, das lesões deixarem Hiper ou hipopigmentação da pele, em $37,5 \%$ dos casos ocorre distrofias de unhas e complicações oculares também podem ser evidenciadas, dentre 


\section{FAG JOURNAL OF HEALTH}

elas se destacam olhos secos, perda de visão e ulceração da córnea (EMERICK, RODRIGUES, et al., 2014).

Recomenda-se que os paciente evitem se expor ao agente causadora síndrome (BULISANI, SANCHES, et al., 2006).

O diagnóstico diferencial da SSJ se com doenças que envolvem a descamação da pele, em especial o eritema multiforme maior, A síndrome de hipersensibilidade ou o eritema induzido por fármaco com eosinofilia, mas também temos a dermatite esfoliativa por psoríase, dermatite do linfoma, queimadura, linfadenopatia angio-imunoblástica, exantemas virais, sífilis secundaria, gengivoestomatite herpética, síndrome da pele escaldada estafilocócica, doença enxerto versus hospedeiro e vasculite (BULISANI, SANCHES, et al., 2006) (WONG, MALVESTITI e HAFNER, 2016).

O tratamento se baseia no diagnóstico precoce da síndrome e a interrupção dos supostos fármacos que possam estar causando a síndrome, sendo as drogas de alto risco para causar a SSJ as principais a serem removidas. O tratamento deve ser feito em unidade de cuidados médios ou intensivos, preferencialmente em unidades de queimados, com a administração de soluções e eletrólitos IV. Deve ser realizadas medidas de suporte e intervenções ativas (WONG, MALVESTITI e HAFNER, 2016) (WOLFF, JOHNSON e SAAVEDRA, 2015) (BULISANI, SANCHES, et al., 2006).

Primeiramente o tratamento de suporte deve ser realizado, com o controle da temperatura corporal, hidratação e reposição eletrolítica, cuidados com vias aéreas, controle da dor, acessos venosos em locais distantes da lesões, nutrição adequada, prevenção de úlcera de estresse e se necessário pose ser feita anticoagulação do paciente para evitar tromboembolismo, que é uma importante causa de morbidade e mortalidade (WONG, MALVESTITI e HAFNER, 2016) (BULISANI, SANCHES, et al., 2006).

O tratamento tópico das lesões deve ser realizado como o tratamento de queimaduras. Pode ser usado anestésicos tópicos, que são uteis em aliviar o sintoma de dor das lesões orais. Em áreas sem pele deve ser feito a oclusão com compressas de solução fisiológica (BULISANI, SANCHES, et al., 2006) (WONG, MALVESTITI e HAFNER, 2016). 


\section{FAG JOURNAL OF HEALTH}

Deve também ser realizado um cuidado ocular, com consulta de oftalmologista diariamente, a lavagem com solução fisiológica e colírios deve ser feita a cada duas horas. Se necessário pode ser feito o uso de antibióticos tópicos (BULISANI, SANCHES, et al., 2006).

A administração de glicocorticoides sistêmico ainda não é um consenso e é muito debatido, em alguns estudos a administração em altas doses no início dos sintomas se mostrou benéfico para diminuir a morbidade e mortalidade, porém, em estágios tardios esses medicamentos estão contraindicados, pois em alguns casos teve aumento de taxas de infecção secundaria e sepse (WOLFF, JOHNSON e SAAVEDRA, 2015) (AZULAY, 2013).Essa complicação é explicada porque o uso sistêmico de corticosteroides pode prolongar o processo de cicatrização das lesões, aumentando as chances de infecções (GHISLAIN e ROUJEAU, 2002).

O uso de imunoglobulinas IV em dose alta, 0,75 a $1 \mathrm{mg} / \mathrm{kg} / \mathrm{dia}$, por 4 dias (AZULAY, 2013), se mostrou eficaz para frear a evolução da síndrome, pois contem naturalmente anticorpos contra o receptor Fas, porém, estudos não demonstram efeitos na progressão do desprendimento ou na velocidade de renovação ou reconstrução da epiderme (GHISLAIN e ROUJEAU, 2002) (BULISANI, SANCHES, et al., 2006).

Em alguns casos a Plasmaferese foi benéfico aos pacientes, entretanto, não houve uma significativa alteração da mortalidade ou do tempo de hospitalização. Também foi proposto o uso de ciclofosfamida, em que todos os pacientes tratados com a droga sobreviveram, mas também tem relatos de casos em que a ciclofosfamida induziu a SSJ (GHISLAIN e ROUJEAU, 2002) (BULISANI, SANCHES, et al., 2006).

\section{METODOLOGIA}

Este relato de caso foi feito a partir de uma pesquisa descritiva transversal. Os dados clínicos foram obtidos através de prontuário médicos, de relatórios de enfermagem e de arquivos laboratoriais de uma paciente que desenvolveu SSJ. Foi feita a tabulação dos dados e posteriormente desenvolvido o artigo. Para a pesquisa e revisão de literatura foi utilizado a base de dados Pubmed e Scielo por meio dos descritores "Síndrome de Stevens-Johnson, Necrólise Epidérmica Tóxica, fenitoína, hemorragia intraparenquimatosa e meningiomas". No trabalho foi relatado um caso de uma paciente 


\section{FAG JOURNAL OF HEALTH}

que desenvolveu a síndrome de Stevens-Johnson associada a fenitoína em um pós operatório de neurocirurgia. Foi pesquisado as causas, consequências e tratamento para a síndrome de Stevens-Johnson, tal qual as diversas interações medicamentosas que poderiam ter sido causadoras do quadro da paciente. Também foi realizado uma breve descrição sobre o que são meningiomas e hemorragias intracranianas e seus tratamentos, visto que o quadro inicial da paciente se deu por conta destas duas patologias. Está pesquisa tem como objetivo levar conhecimento sobre o assunto para o mundo acadêmico e da área da saúde e fazer com que próximos pacientes que desenvolvam a síndrome tenham diagnóstico, suporte e tratamento rápido e ideal para o seu desfecho favorável, diminuindo a mortalidade e morbidade dos futuros acometidos pela síndrome. O trabalho está de acordo com a resolução 466/2012 do Conselho Nacional de Saúde e, tem a aprovação do Comitê de Ética e Pesquisa, com CAAE de número 11613019.6.0000.5219, de acordo com o parecer 3.318.087.

\section{RELATO DE CASO}

Paciente G.F.T., 56 anos, feminino, com história pregressa de hipertensão arterial sistêmica, diabetes melitos, dislipidemia e meningioma cerebral há 6 anos, deu entrada no hospital para realizar cirurgia eletiva de ressecção de Meningioma. Realizada a neurocirurgia sem intercorrências a paciente foi encaminhada à UTI para pós operatório. Após dois dias houve um pico hipertensivo resultando em um rebaixamento do nível de consciência e com evidências de anisocoria a direita. Foi realizado tomografia computadorizada de crânio que evidenciou uma hemorragia intraparenquimatosa frontal à direita, medindo $3,5 \mathrm{~cm}$ de diâmetro e apresentando edema perilesional.

De início foi realizado medidas de proteção cerebral com administração de manitol, sedação com midazolam e fentanil e intubação orotraqueal com hiperventilação mecânica. Em seguida a paciente foi submetida a craniotomia para drenagem do hematoma.

Após a drenagem cirúrgica a paciente retorna a UTI já com pupilas isocóricas e continua em sedação por mais dois dias. Após a retirada da sedação a paciente evolui com melhora progressiva do nível de consciência, somente apresentando oscilação dos níveis pressóricos, sendo administrado nitroprussiato de sódio para controle. 


\section{FAG JOURNAL OF HEALTH}

Foi feita a extubação após 4 dias da drenagem do hematoma e a paciente seguiu melhorando progressivamente até receber alta da UTI 12 dias após a ressecção do tumor, e alta hospitalar, com acompanhamento ambulatorial, após 17 dias com prescrição de nebivolol, olmersartana, esomeprazol e fenitoína.

Paciente retornou ao pronto socorro do mesmo Hospital dez dias após a alta hospitalar relatando hiperemia em face e membros superiores que se iniciou há 4 dias, suspendendo por conta própria a fenitoína, Esomeprazol, Bactrim® e cetoprofeno, os dois últimos para tratamento de infecção do trato urinário.

Ao exame físico a paciente apresentou-se em bom estado geral, eupneica, acianótica, anictérica e afebril, lúcida e orientada em tempo e espaço, com os seguintes sinais vitais: pressão arterial (PA) de $130 \times 80 \mathrm{mmHg}$, frequência cardíaca (FC) de 76 batimentos por minuto, bulhas rítmicas normofonéticas e sem sopros, murmúrio vesicular presente bilateralmente sem ruídos adventícios, abdome indolor e sem vísceromegalias, pulsos amplos e simétricos, sem edema de membros inferiores. Presença de rash eritemato-pruriginoso difuso que desapareciam a digitopressão, com acometimento de mucosa oral e associado a mialgia difusa. Quadro compatível com a hipótese diagnostica de SSJ.

Alguns exames laboratoriais pedidos tiveram resultado de: Hemácias 3,78 milhões

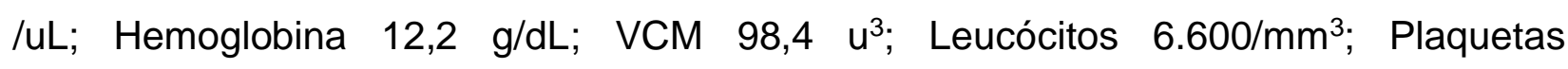
278.000/mm³; Creatinina 0,58 mg/dL; Ureia15,6 mg/dL; Sódio 139,3 mEq/L; Potássio $3,79 \mathrm{mEq} / \mathrm{L}$; Proteína C Ultrassensível $4,49 \mathrm{mg} / \mathrm{dL}$

A conduta imediata foi a suspensão da fenitoína e do Bactrim ${ }^{\circledR}$ e início de prednisona 60 miligramas ao dia e levofloxacino para continuar o tratamento da Infecção do trato urinário. No dia seguinte foi feita a alteração da prednisona por metilpredinisolona 1 grama para o tratamento da reação alérgica.

Quatro dias após o segundo internamento e com a medicação concluída a paciente se apresentava em bom estado geral, não ocorrendo qualquer intercorrências, com melhora progressiva das lesões e sem qualquer outro achado clínico. Recebe alta hospitalar com prescrição de prednisona 40 miligramas ao dia por 5 dias e Levofloxacino. 


\section{FAG JOURNAL OF HEALTH}

\section{DISCUSSÃO}

Os meningiomas são neoplasias primarias do sistema nervoso central mais frequentes e mais comum, correspondendo a 22,4\% destas patologias (TORRES, MADALOZZO, et al., 1996). Se originam das células da aracnoide e, na maioria dos casos, são tumores benignos (FIGUEREDO, AGUIAR, et al., 1998). São predominantes no sexo feminino, com uma relação de 2,2 mulheres para cada homem e a faixa etária mais acometida por este tipo de tumor é entre os 50 e 70 anos, não sendo frequente o aparecimento em indivíduos abaixo dos 20 anos (TORRES, MADALOZZO, et al., 1996).

A maioria dos meningiomas não necessitam de uma intervenção imediata, podendo ser acompanhados durante anos (ROWLAND, 2011). No caso relatado acima, a paciente esteve em acompanhamento neurológico de meningioma por 6 anos e, após novas avaliações o tratamento cirúrgico se mostrou o mais adequado para a paciente. $\mathrm{Na}$ literatura, a intervenção cirúrgica se mostra necessária se, durante o acompanhamento, o paciente apresentar sintomas significativos ou havendo uma evolução radiológica do tumor.

O tratamento de escolha para os meningiomas é a ressecção cirúrgica do tumor e a excisão completa pode levar a cura, porém, a recorrência de um meningioma não é baixa, recidivando em aproximadamente $20 \%$ dos pacientes em 5 anos e em $25 \%$ após 10 anos (ROWLAND, 2011) e está diretamente relacionada ao grau de ressecção (FIGUEREDO, AGUIAR, et al., 1998). Outros tratamentos também estão disponíveis, porém a cirurgia é o mais importante. A radioterapia, tratamento hormonal antiestrogênico e quimioterapia são algumas das opções (ROWLAND, 2011).

Uma das complicações do período pós-operatório de neurocirurgia é a hemorragia intraparenquimatosa, correspondendo a $2,4 \%$ das complicações no período pósoperatório imediato e 5,5\% no período pós-operatório tardio (SIQUEIRA e DICCINI, 20117). As principais causas de hemorragia intracraniana (HIC) são malformações vasculares, uso de drogas e hipertensão arterial sistêmica (HAS) (BERNARDO , FADLALLAH, et al., 2017). A paciente já apresentava história pregressa de HAS e, após dois dias da ressecção do meningioma apresentou um pico hipertensivo, evoluindo com rebaixamento do nível de consciência e anisocoria, o que levou a equipe médica a pensar em um episódio de HIC. Com um exame de neuroimagem prontamente solicitado, sendo 


\section{FAG JOURNAL OF HEALTH}

que a literatura coloca a tomografia computadorizada de crânio como uma boa opção de diagnóstico por ter uma sensibilidade elevada para o diagnóstico de HIC (PONTESNETO, OLIVEIRA-FILHO, et al., 2009), o diagnóstico foi confirmado e o tratamento foi proposto.

Geralmente a HIC se apresenta com um déficit neurológico focal de aparecimento rápido e brusco, que tem progressão nos seguintes minutos e horas. Os sintomas vão ser de acordo com a região cerebral acometida, podendo se manifestar de diferentes maneiras (PONTES-NETO, OLIVEIRA-FILHO, et al., 2009).

A conduta adequada para o tratamento da HIC se dá com um controle agressivo e o mais rápido possível da hipertensão arterial, com objetivo de evitar a expansão do sangramento. Em pacientes com sinais de hipertensão intracraniana algumas medidas devem ser tomadas, como por exemplo a elevação da cabeceira em 30 graus, sedação, doses moderadas de manitol a $20 \%$, solução salina hipertônica e hiperventilação para atingir PaCO2 entre 28 e 32 mmHg (PONTES-NETO, OLIVEIRA-FILHO, et al., 2009), estando de acordo com a conduta tomada pela equipe médica, que iniciou manitol, fez sedação com midazolam + fentanil e a hiperventilação mecânica invasiva. Também é recomendado fazer terapia hemostática com rFVIla, que diminui expansão do hematoma, e drogas antiepiléticas profiláticas (PONTES-NETO, OLIVEIRA-FILHO, et al., 2009).

A drenagem cirúrgica é um tanto quanto controversa, para Pontes-Neto os pacientes devem ser tratados clinicamente e se apresentarem deterioração do quadro neurológico deve ser proposto a conduta cirúrgica (PONTES-NETO, OLIVEIRA-FILHO, et al., 2009). Também compatível com a conduta tomada no caso relatado, que após a paciente apresentar rebaixamento do nível de consciência e a confirmação diagnostica de HIC, foi prontamente indicada a drenagem cirúrgica do hematoma.

Apesar de todos os avanços clínicos, o prognóstico da HIC ainda não é bom, com elevadas taxas de mortalidade e incapacidade, em torno de 35 a $52 \%$ dos pacientes vão a óbito no final do primeiro mês (PONTES-NETO, OLIVEIRA-FILHO, et al., 2009).

$\mathrm{Na}$ alta hospitalar a paciente recebeu prescrição de fenitoína como uma conduta profilática ao desenvolvimento de crises convulsivas, a qual foi a primeira hipótese de estar causando as lesões que a paciente veio a apresentar dez dias após a alta hospitalar, considerando que a fenitoína é classificada como um fármaco de alto risco de 


\section{FAG JOURNAL OF HEALTH}

causar a Síndrome de Stevens-Johnsosn (WONG, MALVESTITI e HAFNER, 2016) e que as chances de a droga causar a síndrome é de 8,8 pessoas para cada 10.000 pessoas (D'AVILA, FIGUEIREDO e TEIXEIRA, 2012). Outra hipótese foi o uso do antimicrobiano composto por sulfametoxazol + trimetroprima, prescrito em outro serviço para tratamento de infecção do trato urinário, que é responsável por $66,6 \%$ das internações hospitalares e por reações adversas a drogas (FALCÃO, SANTOS, et al., 2008).

Também devemos levar em consideração que, a fenitoína pode ter seu metabolismo, que é hepático, inibido pelo uso concomitante de sulfametoxazoltrimetroprima (Bactrim ${ }^{\circledR}$ ), mesmo em doses normais do fármaco, que acarreta em um aumento de $39 \%$ no tempo de meia vida e uma diminuição de $27 \%$ na taxa de clearence metabólico da fenitoína, podendo aumentar os riscos de toxicidade e sendo necessário um ajuste da dose da fenitoína durante o tratamento concomitante (HANSEN, KAMPMANN, et al., 1979). Com isso a hipótese de interação medicamentosa entre os dois fármacos pode explicar o desenvolvimento da SSJ no caso relatado.

Os outros medicamentos utilizados pela paciente durante o período de internamento até o aparecimento das lesões não apresentam interações medicamentosas ou as interações presentes não são relevantes para o caso atual (COORDENAÇÃO DE FARMÁCIA DO HOSPITAL DAS CLÍNICAS DA UNIVERSIDADE FEDERAL DE GOIÁS, 2011).

Tendo em vista os fármacos utilizados pela paciente e as interações desses medicamentos, surge a hipótese de que a SSJ apresentada pela paciente possa ter aparecido em decorrência de várias interações medicamentosas entre estes fármacos, que elevaram os níveis plasmáticos da fenitoína e favoreceram o aparecimento das lesões.

Após o aparecimento das lesões a própria paciente parou de utilizar a fenitoína e o Bactrim $\AA$, conduta que foi mantida pela equipe médica. De acordo com diversos autores a retirada da droga causadora é a principal conduta no tratamento da síndrome e sabendo que uma das principais drogas causadoras da SSJ é a fenitoína, a retirada do medicamento foi de extrema importância para a evolução clínica da paciente.

Também foi prescrito inicialmente a prednisona $60 \mathrm{mg} / \mathrm{dia}$ e, para substituir 0 Bactrim $\AA$, foi prescrito levofloxacino. Como já foi falado acima, o tratamento com 


\section{FAG JOURNAL OF HEALTH}

glicocorticoides sistêmicos ainda não é um consenso entre os estudos, porém, ao início dos sintomas o uso desses medicamentos se mostrou benéfico para reduzir e morbidade e mortalidade dos pacientes (WOLFF, JOHNSON e SAAVEDRA, 2015). Posteriormente a medicação foi alterada para metilpredinisolona $1 \mathrm{~g} \mathrm{e}$, no momento da alta, a prednisona voltou a ser prescrita, porém em dose de $40 \mathrm{mg} / \mathrm{dia}$. No total a paciente fez uso de glicocorticoides por 9 dias e não veio a apresentar qualquer complicação em decorrência do uso.

Após o tratamento houve boa e progressiva evolução clínica e das lesões da paciente, indicando que a administração de glicocorticoides não teve influência no processo de cicatrização das lesões e, portando, a conduta proposta pela equipe médica foi suficiente para o tratamento da SSJ desenvolvida pela paciente

Outras formas de tratamento poderiam ter sido propostas, como por exemplo a administração de imunoglobulina IV e a plasmaferese. Porém, são tratamentos de elevado custo e, como a paciente evoluiu com melhora clínica das lesões somente com a suspensão dos medicamentos e administração de glicocorticoides não se mostrou necessário fazer o uso desse arsenal terapêutico.

A classificação da paciente através do escore de gravidade de SCORTEN ficou prejudicada pela falta de alguns parâmetros necessários, porém, com os parâmetros disponíveis é possível classificá-la com escore de 2, que traduz uma mortalidade de $12,1 \%$. Os parâmetros utilizados foram a idade, que a paciente estava com 56 anos e para positivar o escore é necessário idade maior que 40; a presença de neoplasia, considerando o meningioma que foi ressecado; a dosagem de ureia não foi pontuada, pois ela apresentou uma ureia de $15,6 \mathrm{mg} / \mathrm{dL}$, inferior ao parâmetro do escore que é acima de 28; a frequência cardíaca também estava abaixo do parâmetro de pontuação, que é de uma frequência cardíaca acima de $120 \mathrm{bpm}$, o da paciente se encontrava em $76 \mathrm{bpm}$. Os parâmetros faltantes são a dosagem de bicarbonato sérico, glicemia e a extensão das lesões corporais, que também impossibilita a exata classificação da paciente quanto a SSJ e NET. Sendo assim, a paciente foi classificada como apresentado SSJ. 


\section{FAG JOURNAL OF HEALTH}

\section{CONSIDERAÇÕES FINAIS}

A SSJ e NET são condições que podem levar o paciente a óbito se não diagnosticada e tratada corretamente. Deve-se ter muito cuidado com a prescrição de medicamentos, principalmente os que tem maiores chances de causar a SSJ e sempre avaliar as interações medicamentosas que possam vir a ocorrer no paciente, para que se possa ter cada vez menos casos de SSJ e NET. É sempre necessário ter essas condições como hipótese diagnóstica em casos de reações adversas a medicamentos, fazendo a retirada da medicação o mais prontamente possível e proporcionando aos pacientes um tratamento adequando e uma menor mortalidade.

O tratamento em centros especializados, principalmente em centros para queimados, é o mais indicado, porém, o tratamento inicial pode ser feito em qualquer local, tendo em vista que o principal tratamento é a retirada da suposta medicação causadora.

\section{REFERÊNCIAS}

ARRUDA, J. A. A.; SAMPAIO, G. C. Síndrome de stevens-johnson associada à alopurinol e nimesulida: relato de caso. Revista de Cirurgia e Traumatologia BucoMaxilo-Facial, v. 14, n. 3, Julho/Setembro 2014. Disponivel em: $<$ http://revodonto.bvsalud.org/scielo.php?script=sci_arttext\&pid=S180852102014000300010>.

AZULAY, R. D. Dermatologia. 6. ed. Rio De Janeiro : GUANABARA KOOGAN LTDA, 2013.

BASTUJI-GARIN, S. et al. Clinical Classification of Cases of Toxic Epidermal Necrolysis, Stevens-Johnson Syndrome, and Erythema Multiforme. Archives of dermatology, v. 129, n. 1, p. 92-96, Janeiro 1993. Disponivel em: $<$ https://jamanetwork.com/journals/jamadermatology/article-abstract/554700>. BERNARDO , T. T. et al. Hemorragia cerebral intraparenquimatosa em paciente com doença de Christmas. Revista Científica da FMC, v. 12, n. 3, p. 4, Dezembro 2017. Disponivel em: <http://www.fmc.br/ojs/index.php/RCFMC/article/download/101/159/>. BULISANI, A. C. P. et al. Síndrome de Stevens-Johnson e necrólise epidérmica tóxica em medicina intensiva. Revista Brasileira de Terapia Intensiva, v. 18, n. 3, julho 2006. Disponivel em: <http://www.scielo.br/scielo.php?script=sci_arttext\&pid=S0103507X2006000300012>. 
GOIAIS. Coordenação De Farmácia Do Hospital Das Clínicas Da Universidade Federal De Goiás. Guia de Interações Medicamentosas. Universidade Federal de Goiais. Goiânia. 2011. Disponível em:

$<$ https://farmacia.hc.ufg.br/up/734/o/Guia_de_Interacoes_Medicamentosas.pdf?140905 5761>. Acesso em: 5 jul. 2019.

D'AVILA, R.; FIGUEIREDO, E. G.; TEIXEIRA, M. J. A síndrome de Stevens-Johnson em pacientes neurocirúrgicos. Arquivos Brasileiros de Neurocirurgia, v. 31, n. 04, 2012. Disponivel em: <https://www.thiemeconnect.com/products/ejournals/abstract/10.1055/s-0038-1625743>.

EMERICK, M. F. B. et al. Síndrome de Stevens-Johnson e Necrólise Epidérmica Tóxica. Revista Brasileira de Enfermagem, Brasilia, v. 67, n. 6, p. 898-904, Novembro/Dezembro 2014. Disponivel em: $<$ http://www.scielo.br/scielo.php?script=sci_arttext\&pid=S0034$71672014000600898 \&$ Ing $=p t \& t \mid n g=p t>$. ENSINA, L. F. et al. Reações de Hipersensibilidade a Medicamentos - Parte III. Revista Brasileira de Alergia e Imunopatologia, v. 32, n. 5, 2009. Disponivel em: <http://www.sbai.org.br/revistas/Vol325/N_ART\%205-09\%20-\%20GP\%20\%20Rea\%C3\%A7\%C3\%B5es\%20de\%20Hipersensibilidade\%20a\%20Medicamentos\% 20-\%20parte\%20III.pdf>.

FALCÃO, P. G. C. B. et al. Síndrome de Stevens-Johnson associada ao uso de antimicrobiano. Revista Gaucha de Odontologia, Porto Alegre, v. 56, n. 3, p. 337-340, Julho/Setembro 2008. Disponivel em: <http://www.revistargo.com.br/include/getdoc.php?id=2582>.

FIGUEREDO, E. G. et al. Meningiomas supratentoriais: diagnóstico, resultados cirúrgicos e complicações. Arquivos de Neuro-Psiquiatria, v. 56, n. 3A, setembro 1998. Disponivel em: <http://www.scielo.br/scielo.php?script=sci_arttext\&pid=S0004282X1998000300012>.

GHISLAIN, P.-D.; ROUJEAU, J.-C. Treatment of severe drug reactions: StevensJohnson Syndrome, Toxic Epidermal Necrolysis and Hypersensitivity syndrome.

Dermatology Online Journal, v. 8, n. 1, Junho 2002. Disponivel em: $<$ https://escholarship.org/uc/item/97d8t291\#main>.

HANSEN, J. M. et al. The Effect of Different Sulfonamides on Phenytoin Metabolism in Man. Journal of Internal Medicine, v. 205, n. S624, p. 106-110, Janeiro/Dezembro 1979. Disponivel em: <https://www.ncbi.nlm.nih.gov/pubmed/284708>.

HARR, T.; FRENCH, E. Toxic epidermal necrolysis and Stevens-Johnson syndrome. Orphanet Journal of Rare Diseases, 5, n. 39, 16 Dezembro 2010. Disponivel em: $<$ https://ojrd.biomedcentral.com/articles/10.1186/1750-1172-5-39>.

PONTES-NETO, O. M. et al. Diretrizes para o manejo de pacientes com hemorragia intraparenquimatosa cerebral espontânea. Arquivos de Neuro-Psiquiatria, v. 67, n. 3b, setembro 2009. Disponivel em:

$<$ http://www.scielo.br/scielo.php?script=sci_arttext\&pid=S0004-282X2009000500034>. ROWLAND, L. P. M. Tratado de Neurologia. 12. ed. Rio de Janeiro : Guanabara Koogan LTDA., 2011. 


\section{FAG JOURNAL OF HEALTH}

SIQUEIRA, E. M. P.; DICCINI, S. Complicações pós-operatórias em neurocirurgia eletiva e não eletiva. Acta Paulista de Enfermagem, v. 30, n. 1, p. 101-108, Fevereiro 20117. Disponivel em: <http://www.scielo.br/scielo.php?pid=S0103$21002017000100101 \&$ script=sci_abstract\&tIng=pt $>$. TORRES, L. F. et al. Meningiomas. Epidemiological and anatomopathological study of 340 cases. Arquivos de Neuro-Psiquiatria, São Paulo, v. 54, n. 4, maio 1996.

Disponivel em: <http://www.scielo.br/pdf/anp/v54n4/01.pdf>. WOLFF, K.; JOHNSON, R. A.; SAAVEDRA, A. P. Fitzpatrick Atlas de Dermatologia Clínica. 7. ed. [S.I.]: AMGH, 2015.

WONG, A.; MALVESTITI, ; HAFNER, D. F. S. Stevens-Johnson syndrome and toxic epidermal necrolysis: a review. Revista da Associação Médica Brasileira, v. 62, n. 5, Agosto 2016. Disponivel em:

$<$ http://www.scielo.br/scielo.php?script=sci_arttext\&pid=S0104$42302016000500468 \&$ Ing =en\&nrm=iso\&tIng $=$ en $>$. 